\title{
Social Media Platforms as Artistic Medium
}

\author{
Steven Aishman \\ Royal College of Art \\ London, UK \\ saishman1@gmail.com
}

\section{INTRODUCTION}

This paper proposes to view the meaning of social media artwork as being grounded in a Deleuzian assemblage. Analysis of social media art is best started from a rhizomatic perspective due to its grounding in an assemblage rather than an essentialised perspective. This paper will analyse two artists as examples of how their work is ground in an assemblage and is best approached rhizomatically.

\section{SOCIAL MEDIA AS ASSEMBLAGE}

In $A$ thousand plateaus, Deleuze and Guattari describe the components and functions of an assemblage:

On a first, horizontal, axis an assemblage comprises two segments, one of content, the other of expression. On the one hand it is a machinic assemblage of bodies, of actions and passions, an intermingling of bodies reacting to one another; on the other hand it is a collective assemblage of enunciation, of acts and statements, of incorporeal transformations attributed to bodies. Then on a vertical axis, the assemblage has both territorial sides, or reterritorialized sides, which stabilize it, and cutting edges of deterritorialization, which carry it away. (Deleuze \& Guattari 2007, pp. 97-98)

Social media platforms can be theoretically grounded as Deleuzian assemblages because the meaning of any post on a social media site is always contingent and constantly being deterritorialised as Deleuze and Guattari describe. Within the constraints of the social media platform, users make post that have a particular meaning to them, but once posted, the meaning of the post is immediately deterritorialised by comments, likes, spam, adjacent posts, advertising etc. which are all Deleuzian "lines-of-flight" (Deleuze and Guattari 2007 , p. 9) and the meaning of the post becomes another assemblage. For example, this perpetual deterritorialisation of the social media assemblage can be seen in a Facebook post. Users post to
Facebook with the specific goal of having the meaning of the post deterritorialised through increased numbers of likes and comments. In this way, the meaning of social media posts is inherently contingent as the meaning of a Facebook post with no likes has a significantly different meaning from a post with one million likes. Studies indicate that one of the primary reasons people use social media is for their posts to generate likes and comments and if they do not receive them, users become depressed and anxious. (Primack et al. 2017)

\section{ARTISTS USING SOCIAL MEDIA AS ASSEMBLAGE}

Artists using social media platforms are grounding the meaning of their work in contingency. Contingent meaning is certainly not unique to social media art and as contingency can be found in installation art, performance art, etc. Social media cannot be defined as utilising any specific mode of contingency, but rather, any analysis of social media art is best started from a rhizomatic perspective due to social media's grounding in a contingent assemblage. A rhizomatic perspective allows for multiple entry and exit points to the artwork that allows for the meaning of the artwork to change contingently over time. This is different from other theoretical frames that may seek to begin an analysis by attempting to ground a medium within an essentialised medium specific perspective as Greenberg did when he said artists should use the features that are "unique to the nature" (Greenberg 1960) of a particular medium.

Julia Kaganskiy, editor of the Creators Project, has said, "When artists use social media they are working in a medium of our time." (Pollack 2011, p. 12) There are many examples of artists using social media platforms as a material frequently in conjunction with other media. For example, the artwork "Rachel is" of Rachel Perry Welty (2009) uses Facebook as a medium where she updated her Facebook status every minute for 16 hours. Welty's work is arguably a performance piece 
enacted on the social media platform, but she has said that she considers social media, "a material like oil paint or clay or a pencil on paper". (Xiao 2009 , p. 3) In Perry Welty's work, the material is based in contingency, as all Facebook posts are. The artwork was not just her posting to Facebook, but the comments and likes she has received that continue to potentially evolve. Rachel Perry Welty's Facebook page is still live and her posts can still be liked and comments on, thus potentially changing the meaning of her artwork. Subsequently, the artwork is best approached rhizomatically as it is always changing.

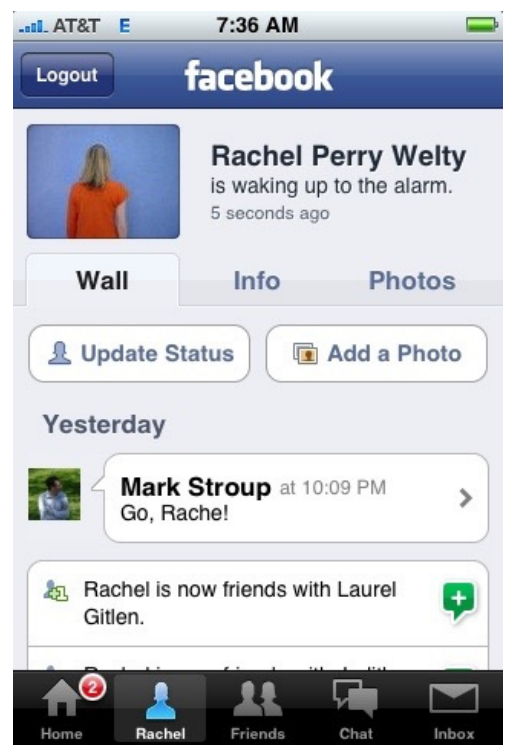

Figure 1: detail from "Rachel is" (Facebook status via iPhone), 11 March 2009. Image courtesy of the artist.

Artists are also using the data aggregated in social media platforms as a medium to create artworks. The "bit.code" of Julius Popp (2009) used an API to display words from social media and news feeds in the V\&A. (Lovell 2009, p. 1) Popp's work also uses social media as a medium, but for his work, he is using the network as a medium rather than the user interface of the social media platform. The API he is using as part of his artwork is not just a tool that is connected to a network, it is part of the network and draws on the activity of the network. If the data that the API is drawing on suddenly disappeared, not only would the artwork immediately stop displaying data, but it would return an error. This is because the data displayed on social media sites is the material that forms the platform. Subsequently, the way social media sites are constructed, they cannot contain zero data. If every Facebook page suddenly had zero data, there would be no platform and Facebook would only return an error. From this perspective, the data collected by social media platforms cannot be viewed as a separate concept that can be extracted from the social media platform because the data is the platform. Subsequently, Popp's work is not data visualisation that can be conducted on extracted and isolated pieces of data, it is still using social media as a material. In this way, the artwork is best approached rhizomatically as the work is different at all times and if the connection to the $\mathrm{API}$ is disrupted, the artwork potentially ceases to exist.

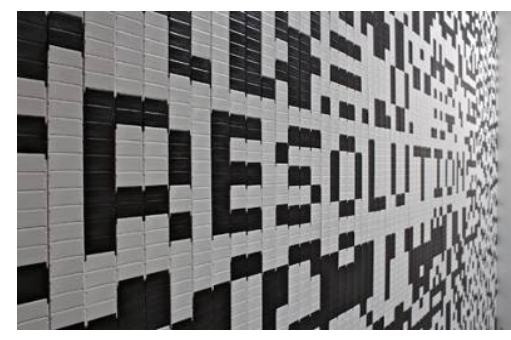

Figure 2: Julius Popp, bit.code 2009. Image courtesy of the $V \& A$.

\section{CONCLUSION}

Social media functions as an assemblage, constantly changing meaning as users contribute to the meaning of a post through likes, comments, etc. The contingency based meaning of social media artwork lends itself to a rhizomatic analysis.

\section{REFERENCES}

Deleuze, G., and Guattari, F. (2007) A Thousand Plateaus. Minneapolis: University of Minnesota Press.

Greenberg, C. (1988) Modernist Painting. In F. Frascina, C. Harrison, \& D. Paul (eds.), Modern Art and Modernism: A critical anthology. London: Chapman.

Lovell, S. (2009) Decode: Julius Popp interview, 3 December.

http://www.wallpaper.com/art/decode-julius-poppinterview (accessed 27 November 2016).

Pollack, B. (2011) The Social Revolution, 1 June. http://www.artnews.com/2011/06/01/the-socialrevolution/ (accessed 27 November 2016).

Primack, B. A., Shensa, A., Escobar-Viera, C. G., Barrett, E. L., Sidani, J. E., Colditz, J. B., and James, A. E. (2017) Use of multiple social media platforms and symptoms of depression and anxiety: A nationally-representative study among U.S. young adults. Computers in Human Behavior, 69, pp. 1-9.

Xiao, A. (2009) "Rachel Is" | An Interview with Rachel Perry Welty, 29 October. http://blog.art21.org/2009/10/29/rachel-is-aninterview-with-rachel-perry-welty/\#.WDrZ8eaLQ2w (accessed 27 November 2016). 